\title{
Thermal Emissivity of Nuclear Graphite as a Function of Its Oxidation Degree (1) -Effects of Density, Porosity, and Microstructure-
}

\author{
Seung-Kuk Seo ${ }^{1}$, Jae-Seung Roh ${ }^{1, \uparrow}$, Eung-Seon $\mathrm{Kim}^{2}$, Se-Hwan $\mathrm{Chi}^{2}$, Suk Hwan Kim ${ }^{1}$ \\ and Sang-Woo Lee ${ }^{1}$ \\ ${ }^{1}$ School of Advanced Materials and System Engineering, Kumoh National Institute of Technology, Gumi, Gyeongbuk 730-701 \\ ${ }^{2}$ Korea Atomic Energy Research Institute (KAERI), Yuseong-gu, Daejeon 305-353 \\ ‘e-mail: jsroh@kumoh.ac.kr \\ (Received July, 2009; Accepted September 10, 2009)
}

\begin{abstract}
Thermal emissivity of commercial nuclear graphites (IG-110, PCEA, IG-430 and NBG-18) following changes in oxidation degrees were examined. Specimens were oxidized to $0 \%, 5 \%$, and $10 \%$ in air flow of $5 \mathrm{l} / \mathrm{min}$ at $600^{\circ} \mathrm{C}$ using a furnace, and the thermal emissivities were measured using an infrared spectrum analyzer. The measuring temperatures for the thermal emissivity were $100^{\circ} \mathrm{C}, 200^{\circ} \mathrm{C}, 300^{\circ} \mathrm{C}, 400^{\circ} \mathrm{C}$ and $500^{\circ} \mathrm{C}$. Also density and porosity of the specimens were observed to compare with thermal emissivity. Results showed that emissivity increased with oxidation, and the $10 \%$ oxidized NBG-18 showed the highest emissivity $(0.890)$ which value is larger for $24 \%$ than the value of as-received specimen. Investigation of factors affecting the emissivity revealed that increases in the surface roughness and porosity due to oxidation were responsible for the increase in emissivity after oxidation.
\end{abstract}

Keywords : Nuclear graphite, Oxidation, Emissivity, Microstructure, Porosity, Density

\section{Introduction}

For producing hydrogen many countries including US, Japan, France, and Korea are making efforts exclusively to develop the safe and high temperature reactor, which is expected to play a important part in producing the electricity as well as the hydrogen in the future. Unlike the light water nuclear reactor that is heated up to $300^{\circ} \mathrm{C}$, the very high temperature reactor (VHTR) is heated up to $900^{\circ} \mathrm{C}$ or more $[1,2]$. The graphite that has the properties of small heat expansion, high thermal conductivity, and high neutron deceleration property could be used for the structure material, reflection material, and deceleration material within the VHTR reactor center. Since the VHTR is, however, operated at the high temperature of $900^{\circ} \mathrm{C}$ or higher, nonactive gases, Ar or He is mostly used for the vapor flowing on the heat exchanger to prevent oxidation of the graphite [3]. Also these gases heat up the water in the heat exchanger at 900 and decompose water into the hydrogen and oxygen. Iodine and sulfur are added and continuously reused for decomposition of the water[2].

On the other hand, the non-active gases, Ar or He gas, have to be jetted and cooled down the reactor when the temperature of VHTR is increased with the any serious problem. However, existence of an extremely small volume of impure substance in the non-active gases may generate critical defects during jet, such as oxidation of the graphite[4-6].

The thermal emissivity of the graphite is very important for the drastic heat release. Up to date, however, there were very little studies done on the thermal emissivity of the nuclear graphite.

The thermal emissivity is a phenomenon appeared on the outside of an object having the thermal energy. The thermal emissivity is used variously in expressing the thermal properties of materials, such as metals, ceramics, plastics, and others. And there are many studies undertaken throughout the industries such as aerospace, fire safety, health and medicine, plastic process, fiber industry, electricity and electronic parts, and others[7-10]. These studies mention that the thermal emissivity is affected depending on the surface shape or tendency of roughness, however it is difficult to find quantitative data[8,9,11 and 12].

This study researched on the effects of changes in the density, porosity and surface structures of nuclear graphite following changes in oxidation degrees on the thermal emissivity of graphite.

\section{Experimental method}

\subsection{Specimens and oxidation processes}

Specimens used in this study are IG-110, PCEA, IG-430, 
Table 1. Properties of IG-110, PCEA, IG-430, and NBG-18 [2,13,14]

\begin{tabular}{ccccccc}
\hline Grade & Manufacture & Forming Method & Source Coke & Grain size $(\mu \mathrm{m})$ & Density $\left(\mathrm{g} / \mathrm{cm}^{3}\right)$ & Porosity $(\%)$ \\
\hline IG-110 & Toyo Tanso & Iso-stat. & Petroleum & 20 & 1.77 & 18.4 \\
PCEA & GrafTech Int. & Extruded & Petroleum & $\sim 360$ & 1.83 & 18.3 \\
IG-430 & Toyo Tanso & Iso-stat. & Pitch & $\sim 10$ & 1.82 & 18.0 \\
NBG-18 & SGL & Vibration & Pitch & $\sim 300$ & 1.85 & 17.8 \\
\hline
\end{tabular}

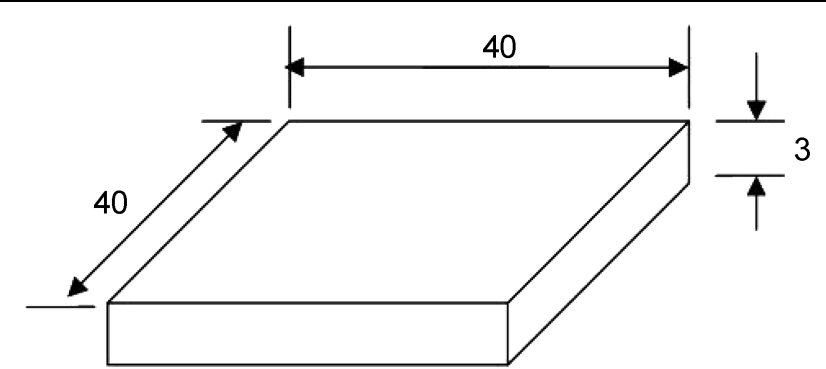

Fig. 1. Specimen dimension (mm) for this study.

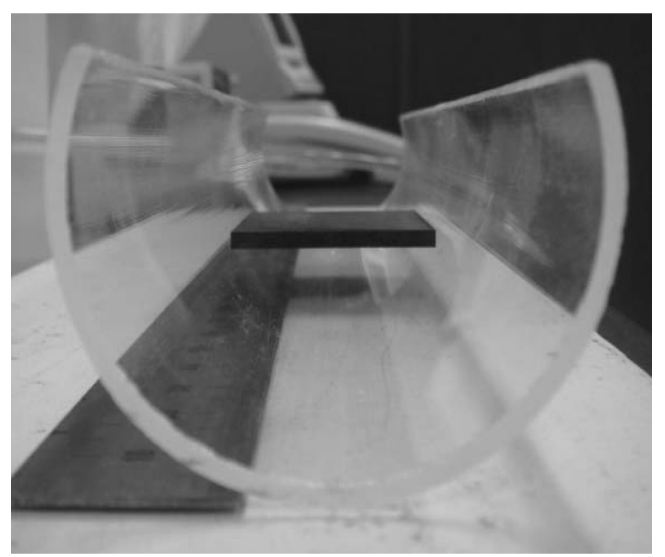

Fig. 2. The sample was loaded on quartz boat.

and NBG-18, and their basic properties are shown in Table 1. According to the data, the IG-110 and IG-430 are manufactured by Toyo Tanso with the iso-static molding method, and the grain sizes are similar for $10 \sim 20 \mu \mathrm{m}$. The source cokes are petroleum for IG-110 and pitch for IG-430. NBG-18 is manufactured by SGL and molded in the vibration method with the grain size of $300 \mu \mathrm{m}$ that is larger than the IG group, and the pitch coke is used for source coke. PCEA is manufactured by GrafTech and molded in the extruded method with the grain size of $360 \mu \mathrm{m}$ that is the largest grain in this study, and the source coke is the petroleum.

The specimens were oxidized at $600^{\circ} \mathrm{C}$ in the air flow of $5 \mathrm{l} / \mathrm{min}$ using the tube furnace. The degrees of oxidation were set to $5 \%$ and $10 \%$ weight losses, because strength of the graphite above $10 \%$ weight loss is weakened to cause the structural problems, and the measurement of thermal emissivity is no longer meaningful.

In order to measure the thermal emissivity, the specimen is cut to size of $40 \times 40 \times 3(\mathrm{~mm})$ as shown in Fig. 1 . This specimen dimension fits specimen holder size of the thermal emissivity measurement device. To minimize the influence of the surface roughness, the specimens are polished to the roughness of $0.5 \mu \mathrm{m}$ or below. For uniform oxidation reaction, the specimens are loaded in the circular-shaped quartz boat in which only two bottom edges of the specimen are in contacted with quarts boat and other sides are open to the atmosphere as shown in Fig. 2.

\subsection{Porosity measurement}

The density and porosity of specimens after oxidation were measured by the Archimedean method. The calculation formulas of density and porosity using the Archimedean method are as follows;

- Porosity $(\%)=\{($ wet weight - dry weight $) /($ wet weightsuspended weight in water $)\} \times 100$

- Density $\left(\mathrm{g} / \mathrm{cm}^{3}\right)=$ dry weight/(wet weight - suspended weight in water)

\subsection{Microstructure observation}

The changes in the microstructures on the specimen surfaces caused by oxidation were observed with the digital camera, optical microscope (OM), and scanning electron microscope (SEM). The OM and SEM microstructures are photographed at a magnification of 50X. Through the microstructure observation the pore distributions and pore size were observed as well. The microstructure observations using an electron microscope were conducted on $60^{\circ}$ tilted specimens in order to observe pore shapes and surface morphologies more clearly.

\subsection{Measurement of thermal emissivity}

After the oxidation experiment, the thermal emissivity of the specimen is measured by the measuring device using the far infrared ray. The thermal emissivities of the specimens with weight loss of $0 \%, 5 \%$, and $10 \%$ were measured at the temperature of $100^{\circ} \mathrm{C}, 200^{\circ} \mathrm{C}, 300^{\circ} \mathrm{C}, 400^{\circ} \mathrm{C}$ and $500^{\circ} \mathrm{C}$, respectively. The measuring room was maintained at $22^{\circ} \mathrm{C}$ and humidity of $35 \%$.

\section{Result}

\subsection{Density and porosity}

Table 2 shows the summary of the density and porosity 
Table 2. A Summary of the Density and Porosity Data

\begin{tabular}{|c|c|c|c|c|c|c|c|c|}
\hline \multirow[t]{2}{*}{ Wt. loss (\%) } & \multicolumn{2}{|c|}{ IG-110 } & \multicolumn{2}{|c|}{ PCEA } & \multicolumn{2}{|c|}{ IG-430 } & \multicolumn{2}{|c|}{ NBG-18 } \\
\hline & $\overline{\text { Density }\left(\mathrm{g} / \mathrm{cm}^{3}\right)}$ & Porosity (\%) & Density $\left(\mathrm{g} / \mathrm{cm}^{3}\right)$ & Porosity (\%) & Density $\left(\mathrm{g} / \mathrm{cm}^{3}\right)$ & Porosity (\%) & Density $\left(\mathrm{g} / \mathrm{cm}^{3}\right)$ & Porosity (\%) \\
\hline $0 \%$ & 1.80 & 11.1 & 1.84 & 7.1 & 1.81 & 11.8 & 1.87 & 6.4 \\
\hline $5 \%$ & 1.74 & 19.7 & 1.73 & 17.9 & 1.74 & 17.5 & 1.80 & 13.5 \\
\hline $10 \%$ & 1.61 & 25.9 & 1.62 & 24.6 & 1.62 & 25.6 & 1.70 & 18.9 \\
\hline
\end{tabular}

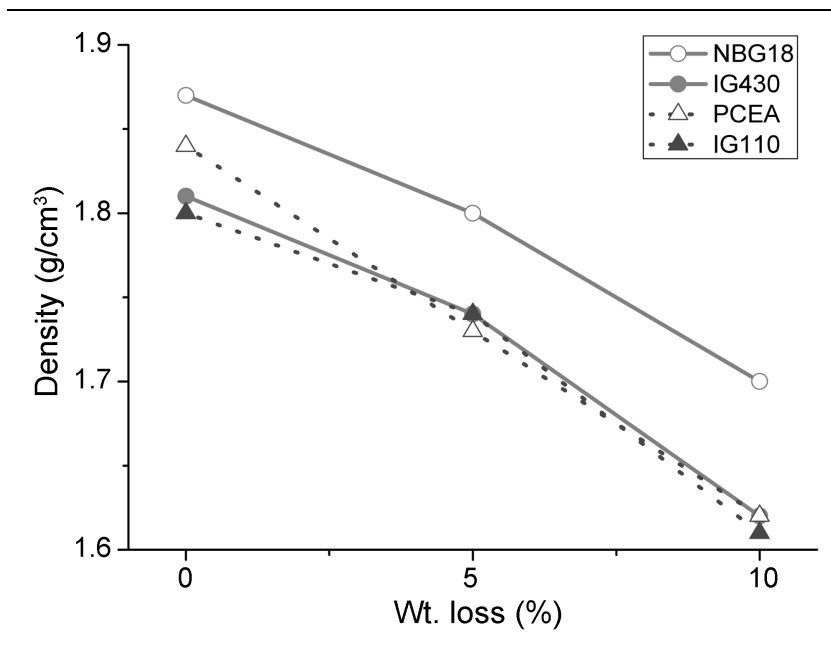

Fig. 3. The density changes as a function of weight losses.

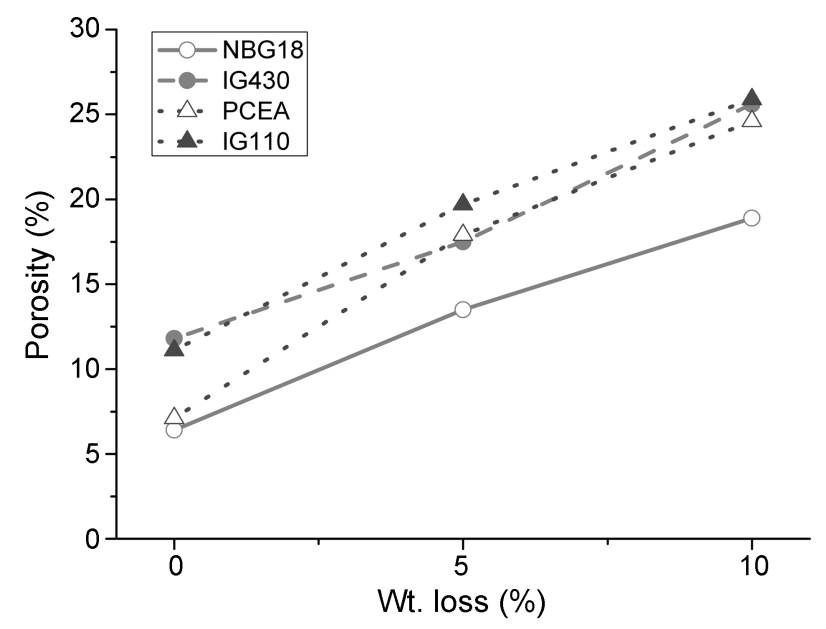

Fig. 4. The porosity changes as a function of weight losses.

measured by the Archimedean method and Fig. 3 and Fig. 4 illustrate the changes in graphs.

Fig. 3 shows an overall tendency under which as the oxidation degree increases the density decreases. Density changes following changes in oxidation degrees are as follows. The density of IG-110 was decreased by oxidation $(0 \% \rightarrow 10 \%)$ from $1.80 \mathrm{~g} / \mathrm{cm}^{3}$ to $1.61 \mathrm{~g} / \mathrm{cm}^{3}$, PCEA from $1.84 \mathrm{~g} / \mathrm{cm}^{3}$ to $1.62 \mathrm{~g} / \mathrm{cm}^{3}$, IG-430 from $1.81 \mathrm{~g} / \mathrm{cm}^{3}$ to $1.62 \mathrm{~g} / \mathrm{cm}^{3}$ and NBG-18 from $1.87 \mathrm{~g} / \mathrm{cm}^{3}$ to $1.70 \mathrm{~g} / \mathrm{cm}^{3}$. Under all conditions before and after oxidation, the density of NBG-18 was the highest and the density of IG-110 was the lowest.

Fig. 4 shows a tendency under which as the oxidation degree increases, the porosity increases as well. By oxidation
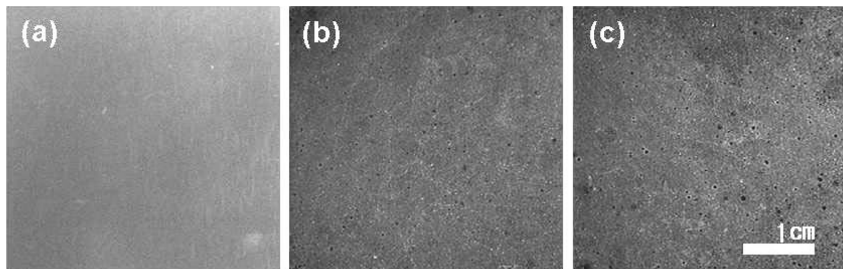

Fig. 5. Overall surface images of IG-110 as a function of oxidation degrees; (a) $0 \%$, (b) 5\%, (c) 10\% wt. loss.

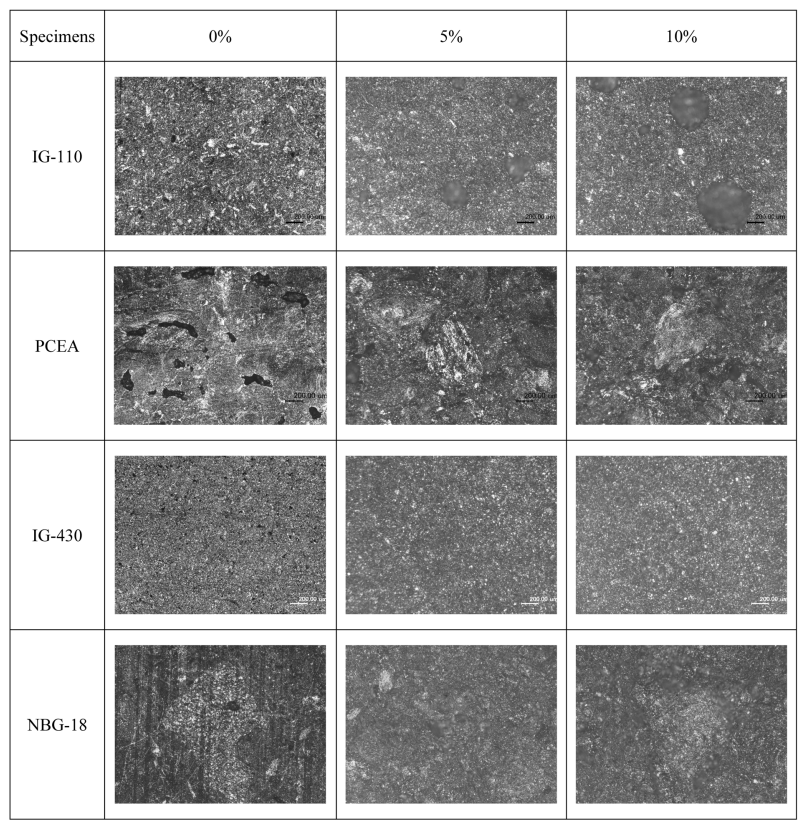

Fig. 6. Change of surface morphologies as a function of oxidation degrees (OM, x50).

$(0 \% \rightarrow 10 \%)$, the porosity of IG-110 was increased from $11.1 \%$ to $25.9 \%$, PCEA from $7.1 \%$ to $24.6 \%$, IG-430 from $11.8 \%$ to $25.6 \%$ and NBG- 18 from $6.4 \%$ to $18.9 \%$. Under all conditions before and after oxidation, the porosity of IG110 was the highest and the porosity of NBG-18 was the lowest. It is not easy to explain the reason why the used graphites showed different porosity after oxidation. It could be assumed that the graphites were manufactured using different processes and raw materials. Therefore the oxidation reactions of the graphites take place by different mechanisms.

\subsection{Microstructure observation}

The surface images of IG-110 taken by digital camera 


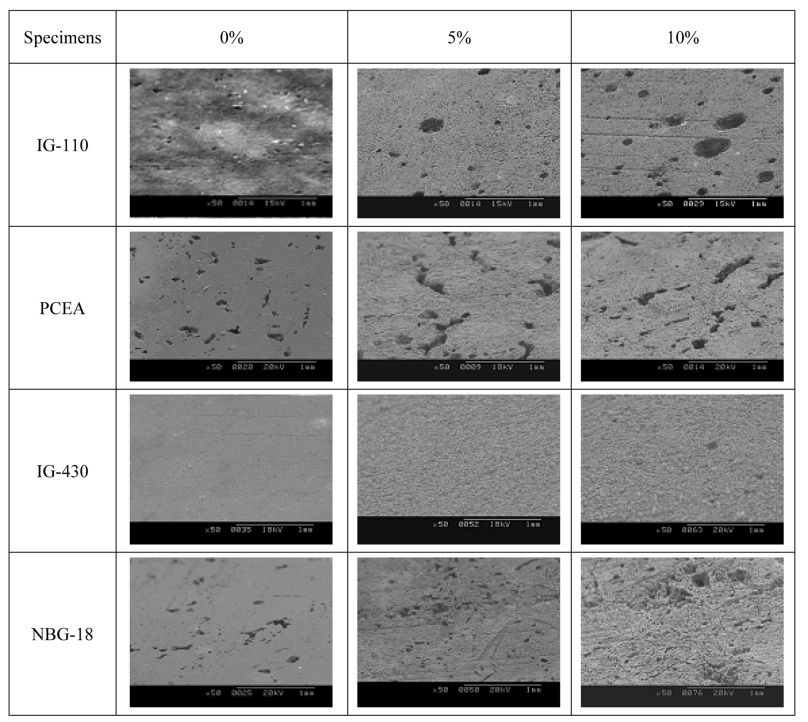

Fig. 7. Change of surfaces morphologies as a function of oxidation degrees (SEM, x50).

were shown in Fig. 5. It can be observed that as oxidation degrees increase, pores are created and grow bigger.

Fig. 6 shows the surface images of the specimens (no polished) observed at a magnification of 50X using an OM. Small pores were observed in the $0 \%$ specimen of IG- 110 , and pores with several tens to $200 \mu \mathrm{m}$ were observed in $5 \%$ specimen. It can be observed that very large pores larger than $300 \mu \mathrm{m}$ have been developed in $10 \%$ specimens rather than small pores. In IG-430, however, the phenomenon of formation and growth of pores on the surface following increases of oxidation degrees could not be observed.

Fig. 7 shows the SEM micrographs of surface morphologies under different oxidation degrees. It can be seen that in the case of IG-110 pores develop well as the oxidation degree increases and in the case of IG-430 large pores are not observed even though prominences and depressions develop on the surface of graphite by oxidation. It can be seen that, in the case of PCEA and NBG-18 pores already exist on $0 \%$ specimens. It is considered that the reason why pores exist on $0 \%$ specimens of PCEA and NBG-18 is the large grain sizes. As shown in the Table 1, the grain size of PCEA and NBG-18 was around $300 \mu \mathrm{m}$ which was larger than that of other types of nuclear graphite.

\subsection{Thermal emissivity}

Table 3 shows changes in thermal emissivity following changes in oxidation degrees. The porosity increased as oxidation degrees increased, and the thermal emissivity showed an increasing tendency as the porosity increased.

Therefore it could be said that increases of porosity resulting from oxidation affect increases of thermal emissivity. However the relationship between two properties is different by the kind of graphite. The specimen with the highest
Table 3. Results of Thermal Emissivity

\begin{tabular}{lccccc}
\hline \multirow{2}{*}{$\begin{array}{c}\text { wt. loss } \\
(\%)\end{array}$} & $\begin{array}{c}\text { Temperature } \\
\left({ }^{\circ} \mathrm{C}\right)\end{array}$ & \multicolumn{4}{c}{ Thermal emissivity } \\
\cline { 3 - 6 } $0 \%$ & 100 & IG-110 & PCEA & IG-430 & NBG-18 \\
\hline 0.681 & 0.731 & 0.682 & 0.737 \\
& 200 & 0.601 & 0.663 & 0.626 & 0.627 \\
& 300 & 0.585 & 0.645 & 0.657 & 0.609 \\
& 400 & 0.582 & 0.587 & 0.646 & 0.538 \\
& 500 & 0.558 & 0.596 & 0.647 & 0.649 \\
$5 \%$ & 100 & 0.786 & 0.861 & 0.815 & 0.847 \\
& 200 & 0.776 & 0.797 & 0.805 & 0.777 \\
& 300 & 0.771 & 0.795 & 0.816 & 0.729 \\
& 400 & 0.759 & 0.681 & 0.818 & 0.681 \\
& 500 & 0.666 & 0.691 & 0.755 & 0.738 \\
$10 \%$ & 100 & 0.835 & 0.866 & 0.854 & 0.890 \\
& 200 & 0.783 & 0.850 & 0.812 & 0.834 \\
& 300 & 0.775 & 0.803 & 0.819 & 0.756 \\
& 400 & 0.764 & 0.718 & 0.824 & 0.694 \\
& 500 & 0.675 & 0.696 & 0.800 & 0.738 \\
\hline
\end{tabular}

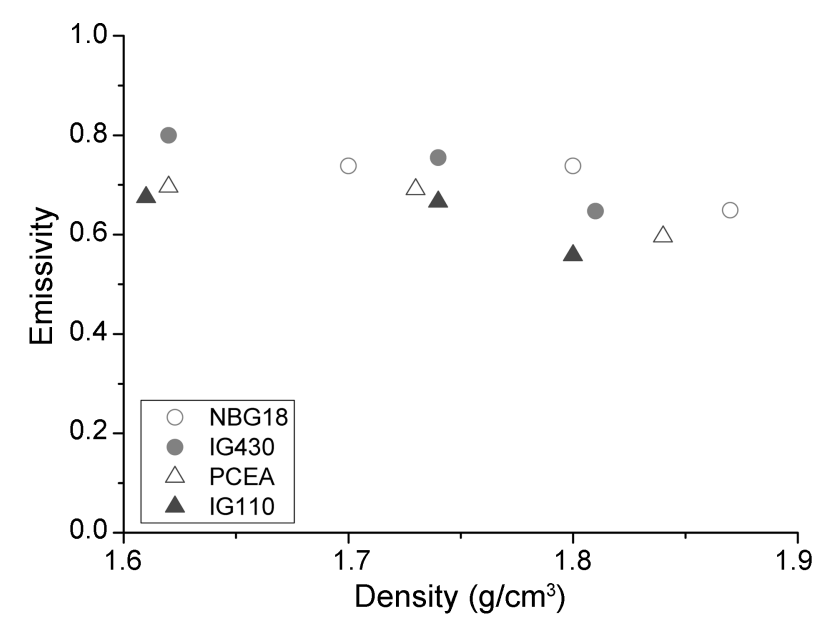

Fig. 8. Relationships between the density and the thermal emissivity.

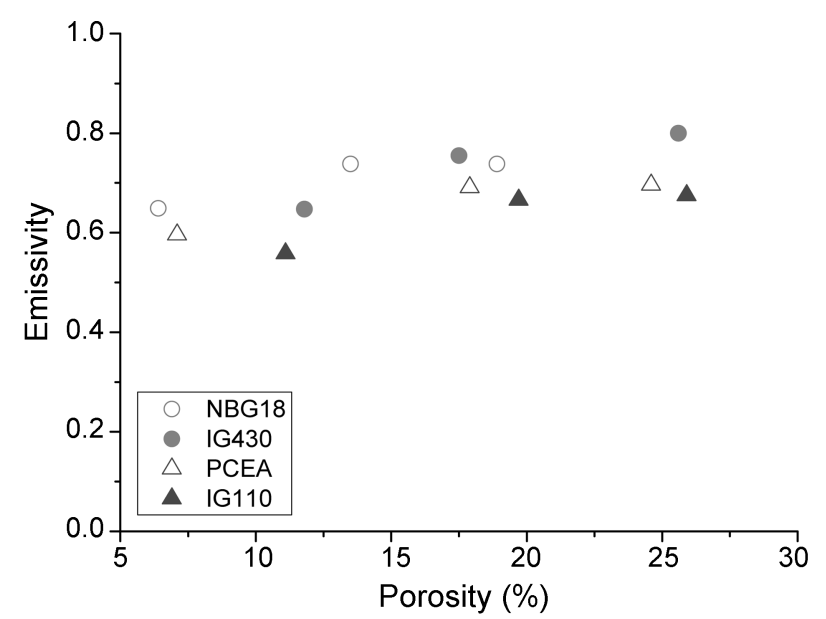

Fig. 9. Relationships between the density and the thermal emissivity. 
thermal emissivity in Table 3 is $10 \%$ oxidized NBG-18 measured at $100^{\circ} \mathrm{C}$, but the decreasing rate may be higher depending on measuring temperatures. Based on the above porosity and density data, NBG-18 has high density and low porosity under all oxidation degrees. As shown in the Table 2, NBG-18 has a grain size of around $300 \mu \mathrm{m}$ which is much larger than IG group. Like NBG-18, PCEA also consists of large grains of around $360 \mu \mathrm{m}$ and it shows second highest value of 0.866 as the emissivity of the $10 \%$ oxidized graphite at $100^{\circ} \mathrm{C}$ of which the porosity is $7.1 \%$. Therefore, evaluation of effects on thermal emissivity should consider not only changes in density and porosity but also microstructures.

Fig. 8 shows a graph that indicates relationships between density and thermal emissivity obtained through integrating all density data for nuclear graphite used in this study. In general, as density increases, thermal emissivity shows a decreasing tendency.

Fig. 9 shows relationships between porosity and thermal emissivity by integrating all porosity data for nuclear graphite used in this study and as porosity increases, thermal emissivity increases as well.

\section{Conclusion}

The thermal emissivities of nuclear graphites following changes in oxidation degrees were studied. The graphite was oxidized in air flow of $5 \mathrm{l} / \mathrm{min}$ at $600^{\circ} \mathrm{C}$ using a furnace, and the thermal emissivities were measured using an infrared spectrum analyzer. The measuring temperatures for the thermal emissivity were $100^{\circ} \mathrm{C}, 200^{\circ} \mathrm{C}, 300^{\circ} \mathrm{C}, 400^{\circ} \mathrm{C}$ and $500^{\circ} \mathrm{C}$. Also density, porosity, and surface roughness of the specimens were observed to compare with thermal emissivity. The results are as follows.

The overall emissivities of oxidized samples were increased with increase of the oxidation degrees. As oxidation degrees increased, density decreased and porosity increased, respectively. PCEA graphite showed the largest changes in density and porosity after oxidation among the all graphite. The density of PCEA graphite decreased in $12.0 \%$ from $1.84 \mathrm{~g} / \mathrm{cm}^{3}$ to $1.62 \mathrm{~g} / \mathrm{cm}^{3}$ and porosity increased in 3.5 times from $7.1 \%$ to $24.6 \%$. SEM observation showed that fine pores of oxidized graphites were developed and grown.

The $10 \%$ oxidized NBG-18 showed the highest emissivity (0.890) which value is larger for $24 \%$ than the value of asreceived specimen. Investigation of factors affecting the emissivity revealed that increases in the surface roughness and porosity due to oxidation were responsible for the increase in emissivity after oxidation.

\section{Reference}

[1] Mitchell, B. C.; Smart, J.; Fok, S. L.; Marsden, B. J. J. Nuclear Materials, 2003, 322, 126.

[2] Luo, X.; Robin, J. C.; Yu, S. Nuclear Engineering and Design, 2004, 227, 237.

[3] Rainer, M.; Hinssen, H. K.; Kerstin, K. Nuclear Engineering and Design, 2004, 227, 281.

[4] Kurumada, A.; Oku, T.; Harada, K.; Kawamata, K.; Sato, S.; Hiraoka T.; McEaney, B. Carbon, 1997, 35(8), 1157.

[5] Idaho National Engineering \& Environmental Laboratory, "Very High Temperature Gas Cooled Reactor Systems", 2002 Winter ANS Meeting, Washington, D.C.

[6] Chunhe, T.; Jie, G.. J. Nuclear Materials, 1995, 224, 103.

[7] Zhao, C. Y.; Lu, T. J.; Hodson, H. P. International Journal of Heat and Mass Transfer, 2004, 47, 2927.

[8] Zueco, J.; Alhama, F. J. Quantitative Spectroscopy \& Radiative Transfer, 2006, 101, 73.

[9] Ball, M.; Pinkerton, H.; Harris, A. J. L. J. of Volcanology and Geothermal Research, 2008, 173, 148.

[10] Gardner, L.; Ng, K. T. Fire Safety Journal, 2006, 41, 185.

[11] Yi, J.; He, X. D.; Sun, Y.; Li, Y. Applied Surface Science, 2007, 253, 4361.

[12] Bellayer, S.; Gilman, J. W.; Rahatekar, S. S.; Bourbigot, S.; Flambard, X.; Hanssen, L. M.; Guo, H.; Kumar, S. Carbon, 2007, 45, 2417.

[13] Kim, E. S.; Kim, Y. W. "Effect of a Thermal Oxidation on the Compressive Strengths of Selected Nuclear Graphites", Transactions of the Korean Nuclear Society Autumn Meeting PyeongChang, Korea, 2007.

[14] Chi, S. H.; Kim, G. C. J. Nuclear Materials, 2008, 381, 9. 